\title{
A valoração econômica da água - uma reflexão sobre a legislação de gestão dos recursos hídricos do Mato Grosso do Sul
}

The economic valuation of the water - a reflection on the legislation of management

of the hídricos resources of the Mato Grosso do Sul

\section{La valorisation de l'eau - une reflexion sûr la legislation de la gestion des resouces} hydiques du Mato Grosso do Sul

La valoración econômica del água - uma refléxion sobre la legislación de la géstion de los recursos hídricos de Mato Grosso do Sul.

Valéria Cristina Palmeira Zago

Recebido em 6/9/2006; revisado e aprovado em 30/11/2006; aceito em 2/2/2007.

\begin{abstract}
Resumo: O valor econômico da água ainda não foi devidamente compreendido pela sociedade, especialmente em regiões que, aparentemente, não há restrições quantitativas. Para que a cobrança seja vista como um instrumento de gestão, em benefício da sociedade, deverá haver um amplo processo de conscientização, com posterior mobilização popular, fazendo-se representar, os diversos setores desta, em organismos de bacia, para as discussões sobre a gestão dos recursos hídricos.
\end{abstract}

Palavras-chave: Cobrança; recursos hídricos; Mato Grosso do Sul.

Abstract: The economical value of water has not been understood yet by society, mainly where quantitative restrictions do not exist. Thus, in order to make the water use fee an instrument of environmental management, bringing benefits to all society, there must be an extensive process of elucidation, with popular mobilization through its diferent sectors organized in basin comittees to discuss the management of hydric resources.

Key words: Water use fees; hydric resources; mobilization.

Résumé: Le valeur économique de l'eau n’a pás encore dûment compris por la societé, spécialement em régions que, apparement, il n'y a pás de restrictions quantitatifs. Pour que le recouvrement soit vu comment um instrument de géstion, em bénéfice de la societé, on devra avoir um ample proc'rss dr conscientisation, avec postérieur mobilisation populaire, à trav'res de la réprésentations des plusieurs sectuers de la societé, em organismes de bassin, por les discutions sûr la géstion des resources hydiques.

Mots-clé: Recouvrement; resources hydiques; Mato Grosso do Sul.

Resumen: El valor econômico del água aún no fue adecuadamnet compreendido por la sociedad, especialmente em régiones que, aparentementte, no hay restriciones cuantitativas. Para que el pagamiento sea visto cómo un instrumento de géstion, em benefício de la sociedad debrá haber uma conscientización, com posterior mobilización de la población, haciendose por representar, los diversos sectores de esta, en organismos de bacia, para las discusiónes sobre la gestión de los recursos hídricos.

Palabras clave: Pagamiento; recursos hídricos; Mato Grosso do Sul.

\section{Introdução}

O termo "racionalização" tem-se tornado bastante corrente em nossa sociedade nas últimas décadas. Os problemas vivenciados pelos brasileiros como a escassez de água no Nordeste e Norte ou as inundações no Sul do país, são reflexos ou mesmo conseqüências, dos progressivos desequilíbrios ambientais, dados pela intensa utilização dos recursos naturais, como meios de produção ou pela degradação destes, geradas pela poluição.

No entanto, a sociedade, pela sua complexidade política, econômica e social, adia a discussão sobre o impasse do modelo eco- nômico vigente, que prenuncia perspectivas nada animadoras, caso não sejam revistos os padrões de desenvolvimento. É óbvio que sem a preservação e recuperação do meio ambiente, não há adequada condição de vida no planeta, porém, ainda prevalece a "ilusão da abundância ou da inesgotabilidade".

No Brasil supõe-se que a água jamais será problema. Ledo engano. Atualmente já o é. O país tem as maiores reservas de água doce do mundo, só proporcionais às suas taxas de desperdício: $40 \%$ na rede pública. Mas a distribuição geográfica irregular e a urbanização crescente pressionam o abastecimento deficiente. $\mathrm{O}$ mau uso também pres-

Engenheira Agrônoma. Profa. Dra. Faculdade de Medicina Veterinária e Zootecnia - UFMS. 
siona as reservas: há crescente contaminação de agrotóxicos, mercúrio dos garimpos e lixo. No Brasil, rio é sinônimo de lixo: 63 \% dos 12 mil depósitos de lixo são corpos d'água. E como a água não é tratada, 63 \% das internações pediátricas e $30 \%$ das mortes infantis com menos de um ano devem-se à falta de saneamento básico. Um problema leva a outro: poluição das águas, morte dos rios, morte das pessoas (LIMA, 2002).

A capacidade de autodepuração da natureza é limitada e só ocorrerá, caso o ecossistema possa ser preservado da contínua degradação ambiental. Contudo, o que tem ocorrido é justamente o contrário, ou seja, a saturação máxima do sistema, tornando-o insustentável, desconsiderando-se as múltiplas inter-relações bióticas e abióticas existentes.

As medidas mitigadoras da degradação dos recursos naturais, que alguns países vêm adotando são diversificadas, principalmente, frente às diferentes realidades em que estão inseridos. Muitas experiências têm sido positivas, outras nem tanto, porém cada situação é única e tem suas inerentes complexidades a serem avaliadas. Entretanto, a valoração da água tem sido quase uma unanimidade entre os países que já a adotaram ou estão em processo de, já que a mesma tem sido cercada de muita polêmica dentre os diversos setores econômicos utilizadores deste recurso.

\section{Valoração econômica do uso dos recursos hídricos}

Todos os processos produtivos são dependentes dos recursos naturais, em maior ou menor expressão. Com o aumento demográfico e maior expectativa de vida, a utilização e a degradação dos recursos ambientais intensificaram-se no último século. Segundo VIANNA et al. (1994), são as distintas formas de se relacionar economicamente com o ambiente, que caracterizam a transformação da natureza em recursos naturais.

Um dos recursos que tem recebido maior impacto é a água. As pressões sobre os recursos hídricos estão diretamente relacionadas ao modelo de desenvolvimento econômico, que se expressa pelo nível de con- sumo da sociedade e pela predominância regional de atividades econômicas distintas. À medida que a água bruta torna-se um recurso hídrico, devido à demanda de atividades antrópicas, também cresce o conflito em torno de sua apropriação e uso, adquirindo valor, pois se torna um bem econômico (BORBA \& MERCANTE, 2001).

Dados atuais mostram que o consumo per capita de água é desigual entre as economias mundiais, no Brasil, que possui a maior disponibilidade hídrica do planeta - 13,8 $\%$ do deflúvio mundial - considerando a diversidade de predominância das atividades econômicas, a derivação social da água está distribuída em $61,2 \%$ do consumo pelo setor agropecuário, 20,8\% por uso doméstico e $18 \%$ para uso industrial (FREITAS \& SANTOS, 1999).

Diante da constatação de que o uso intenso dos recursos naturais nas atividades de produção e consumo nos países industrializados estava ocasionando a degradação desses recursos, sem que houvesse a correspondente contabilização da perda coletiva por isso, no sistema de preços, o princípio poluidor-pagador começou a ser adotado pelos países-membros da OCDE (Organização de Cooperação e Desenvolvimento Econômico), no início da década de 70 (CORDEIRO NETTO, 1999, citado por BROCH, 2001).

$\mathrm{O}$ modelo francês de gestão de recursos hídricos tem sido a principal referência para a construção do arcabouço da legislação brasileira. A cobrança tem sido o instrumento de gestão de regulamentação mais conturbada.

Uma das alegações contrárias à cobrança do uso da água é a sua categorização como mais um imposto. Mas, na realidade, a cobrança difere do tributo - imposto na legislação brasileira por vários princípios, entre eles, o da não vinculação da receita. $O$ imposto, como uma forma de tributo prevista na Constituição Federal, não pode ter destinação pré-definida, fazendo parte das receitas derivadas do Estado. A cobrança pelo uso dos recursos hídricos, conforme disposição legal, deverá ser aplicada nos planos e programas aprovados no Plano de Recursos Hídricos pelo respectivo Comitê da Bacia Hidrográfica, onde foram arrecadados os recursos (PAIVA, 2001). 
Conforme a Lei n. 9.433/97, os recursos arrecadados com a cobrança devem ser aplicados, prioritariamente, na bacia hidrográfica em que foram gerados, e deverão ser utilizados para: financiamento de estudos, programas, projetos e obras incluídos nos Planos de Recursos Hídricos; implantação e custeio administrativo dos órgãos e entidades integrantes do Sistema Nacional de Gerenciamento de Recursos Hídricos (para estas despesas, só poderão ser utilizados até sete e meio por cento) e; em projetos e obras que alterem, de modo considerado benéfico à coletividade, a qualidade, a quantidade e o regime de vazão de um corpo d'água.

Em muitos países, como no Brasil, as águas públicas são consideradas bem inalienáveis, outorgando apenas o direito de uso. Cobra-se, geralmente, a remuneração dos serviços ligados a seu fornecimento, como a adução, o transporte, a distribuição ou regularização. Por esse motivo, o que é visado não é o valor material do bem econômico, mas o do direito à sua utilização $(\mathrm{BROCH}, 2001)$.

Ainda deve ser ressaltado, de forma a evitar confusões, o real objeto dessa cobrança. Ele consiste na cobrança de valores monetários em função da utilização dos recursos hídricos por quem é detentor da outorga nos direitos de uso. A cobrança não será efetuada contra o consumidor da prestação de serviços de tratamento, de abastecimento, de coleta e esgotamento de dejetos (rede de esgotos), mas daqueles que utilizam os recursos hídricos por meio de captação direta dos corpos d'água, incluindo em sua atividade econômica, ou daqueles que os utilizam em sua atividade econômica para, posteriormente, esgotá-lo diretamente no corpo d'água (exemplos: produtores rurais, companhias de abastecimento, empresas geradoras de energia elétrica, indústrias, etc.) (VETORATTO, 2004).

\section{Retrospectiva histórica das discussões sobre a política estadual de recursos hídricos}

O principal setor econômico do Estado de Mato Grosso do Sul é a agropecuária. Nos últimos anos, as culturas agrícolas irrigadas têm crescido, aumentando de 55.600 ha (1996) para 61.400 ha (1998), onde os métodos mais utilizados têm sido aqueles alta- mente consumidores de água, como o pivô central e a irrigação por inundação (CRISTOFIDIS, 1999 citado por BROCH, 2001).

Já o setor industrial engloba $13 \%$ da população ativa e, de acordo com as características vocacionais do Estado, as agroindústrias sobressaem entre as demais atividades industriais implantadas: matadouros, frigoríficos, abatedouros de aves, graxarias, farinheiras, fecularias, laticínios, curtumes, fabricação de bebidas, usinas de açúcar e álcool (BROCH, 2001).

Sabe-se que a atividade econômica que mais consome água é a irrigação de culturas agrícolas, graças às elevadas perdas provocadas pela evapotranspiração. Em termos mundiais, a agricultura utiliza $69 \%$ da água disponível, a indústria consome $23 \%$ e as residências $8 \%$. Em países em desenvolvimento, a utilização de água pela agricultura chega a atingir $80 \%$ (BANCO MUNDIAL, 1994). Na irrigação, o uso consuntivo é elevado, alcançando até $90 \%$; além de carrear agrotóxicos e fertilizantes, poluindo águas superficiais e subterrâneas (BORSOL \& TORRES,1997).

Segundo Martins et al. (2001), sendo um dos parâmetros para a cobrança do uso da água, a quantidade demandada e a qualidade dos efluentes lançados pelos usuários, a agricultura - principal depositária de efluentes químicos e orgânicos sobre corpos d'água em todo o mundo e principal captadora de recursos hídricos - será, portanto, um dos setores mais afetados por essa nova estratégia de racionalização do recurso, razão pela qual tal legislação tem suscitado intranqüilidade para o conjunto dos agricultores.

Nas experiências internacionais de valoração dos recursos hídricos, os usuários agrícolas têm se destacado como os principais opositores à criação de legislação que regulamente a cobrança. O lobby político dos agricultores - principalmente nos países europeus - transformou-se muitas vezes em impasse político, requerendo então negociações setoriais que resultaram na criação de diversas alternativas de subsídios (WORLD BANK WATER DEMAND RESEARCH TEAM, 1993).

Da mesma forma, nos Estados brasileiros, a discussão em torno da cobrança tam- 
bém tem refletido os interesses econômicos dos setores dominantes e fortemente representados politicamente.

O Mato Grosso do Sul foi um dos últimos Estados a sancionar a lei de Recursos Hídricos. O processo de discussão foi iniciado em novembro de 1998, quando a Secretaria de Estado do Meio Ambiente (SEMA) propôs, em caráter de urgência, um projeto de Lei instituindo a Política Estadual de Recursos Hídricos. Nessa ocasião, houve uma audiência pública tratando sobre os dispositivos constantes no referido Projeto de Lei.

A audiência pública foi confusa, polêmica e, as informações referentes à gestão dos recursos hídricos estaduais foram insuficientes. Vários interesses da iniciativa privada e pública foram engendrados no processo da discussão do projeto de lei, gerando várias contraposições, principalmente, por parte do setor agropecuário do Estado, que se opôs radicalmente contra a "cobrança da água" (BROCH et al., 2001).

A SEMA reformulou a proposta após reavaliação do projeto de lei anterior, por meio de amplo trabalho técnico e contratação de consultoria especializada, com recursos do projeto ALTO PARAGUAI (SRH/ GEF/PNUMA/OEA), subprojeto 6.1 Desenvolvimento de um programa de informação pública na Bacia do Alto Paraguai. Propuseram - se atividades que tinham por objetivo incrementar a participação das comunidades municipais no gerenciamento ambiental da BAP, através da informação e conscientização dos usuários.

Estas ações foram iniciadas em maio de 2000, com a apresentação da nova minuta de lei em audiência pública na Assembléia Legislativa - Campo Grande/MS e no município de Porto Murtinho, no dia 20 do mesmo mês. Dentre os setores da sociedade, aquele que se mostrou mais organizado e uníssono sobre o assunto foi o setor agropecuário. No entanto, devido à paralisação temporária das atividades do Projeto GEF Alto Paraguai, houve uma interrupção das ações de divulgação e mobilização popular nos municípios da BAP, programadas no sub-projeto 6.1 .

Estas ações incluíam a apresentação de palestras e distribuição de material informativo, tais como cópias da minuta da lei estadual, folders e cartilhas onde seriam apre- sentados dados relativos à importância ambiental, social e econômica da água (BORBA, 2005, comunicação pessoal).

Após dois anos de discussões e trâmite na Assembléia Legislativa, a Política Estadual de Recursos Hídricos, foi aprovada pela Lei n. 2.406, em 29 de janeiro de 2002. A lei estadual procurou seguir como modelo, a estrutura da Lei Federal n. 9.433/97, respeitando-se as finalidades, os princípios, as diretrizes e os instrumentos. Todavia, diferentemente das leis estaduais de Recursos Hídricos existentes até então, as seções que tratam sobre a outorga e a cobrança ficaram em vários aspectos em desacordo com a legislação federal.

A Lei n. 9.433/97 estabelece que "o regime de outorga de direito ao uso dos recursos hídricos tem por objetivo assegurar o controle quantitativo e qualitativo dos usos das águas e o efetivo exercício dos direitos de acesso à água". Estão sujeitos à outorga, dentre outros, "a derivação ou captação de parcela da água existente em um corpo de água para consumo final, inclusive abastecimento Público ou insumo de processo produtivo".

$\mathrm{O}$ artigo 20, da lei federal, vincula a cobrança à outorga: "Serão cobrados os usos de recursos hídricos sujeitos a outorga", além do que, "Independe de outorga, dentre outras, as derivações, captações e lançamentos considerados insignificantes", e deixa claro no artigo 38 que, "Compete aos Comitês de Bacia Hidrográfica, no âmbito de sua área de atuação, propor ao Conselho Nacional e aos Conselhos Estaduais de Recursos Hídricos as acumulações, derivações e lançamentos de pouca expressão, para efeito de isenção da obrigatoriedade de outorga de direito de uso de recursos hídricos, de acordo com os domínios destes."

A lei estadual $n^{\circ} 2.406 / 02$, ao mesmo tempo em que preconiza a importância da cobrança como instrumento de gestão e traça como objetivos, reconhecer a água como bem econômico e dar ao usuário uma indicação de seu real valor; incentivar a racionalização do uso da água, dentre outros de igual importância; considera como insignificantes e serão isentos da cobrança pelo direito de uso da água as capacitações e derivações empregadas em processo produtivo agropecuário (art. 19 e 20). 
Para que não haja dúvidas quanto à necessidade de isenção do setor agropecuário empresarial, a lei reitera nos artigos 23 e 24, respectivamente: "As agroindústrias que dispuserem de sistemas próprio de captação, tratamento e reciclagem de água, com projetos aprovados pela Secretaria de Estado do Meio Ambiente, Cultura e Turismo, serão isentos da cobrança pelo direito de uso da água" e "Os produtores rurais que mantiverem sistema de irrigação de lavouras, estarão isentos da cobrança pelo direito do uso da água, desde que comprovado o aumento da produtividade agrícola do beneficiado e a não poluição da água".

Um dos maiores problemas nestas emendas apresentadas ao projeto de lei e sancionadas pela Assembléia Legislativa, constituindo agora o escopo da Política Estadual de Recursos Hídricos, é o enfraquecimento dos Comitês de Bacias Hidrográficas, fórum dos municípios e seus setores representativos. Os comitês devem, conforme disposto na legislação federal, elaborar o plano de gestão dos recursos hídricos da bacia, onde constaram todas as diretrizes que nortearam o uso dos demais instrumentos, como outorga e cobrança.

Até o presente momento, para as ações relacionadas à gestão de recursos hídricos, o Mato Grosso do Sul conta apenas com a participação de um comitê de bacia hidrográfica (Comitê de Bacia do Rio Miranda) e um consórcio intermunicipal, que representam embriões para a implantação do Sistema Estadual de Recursos Hídricos. Recentemente, foi regulamentado o Conselho Estadual dos Recursos Hídricos (decreto 11.621 de $1^{\circ}$ de junho de 2004), composto por diversos segmentos da sociedade civil.

Espera-se que, com a representação democrática no Conselho Estadual, haja um debate mais aprofundado sobre estes aspectos contraditórios da lei estadual. Surpreende não haver, até então, um posicionamento dos órgãos jurídicos do Estado quanto às divergências da lei estadual frente à lei federal. De acordo com os preceitos jurídicos, a legislação dos Estados - Membros devem independentemente do assunto a que se refere, atentar as diretrizes federais, podendo quando necessário, ser mais restritiva que aquela.

O reconhecimento do valor econômico da água é o principal indutor ao uso raci- onal desse recurso natural, servindo de base para a instituição da cobrança pela utilização dos recursos hídricos, levando ao equilíbrio entre a oferta e a demanda. O modelo de gestão brasileira possibilitará, como já ocorre em outros países, a adoção ou busca de tecnologias mais limpas e que proporcionem, conseqüentemente, maior sustentabilidade dos processos produtivos. Especificamente, no caso dos irrigantes, poder-se-ia, mudar o manejo da água, modificar as técnicas de irrigação, etc, diminuindo desta forma, os impactos ambientais da atividade, conduzindo a melhorias para toda a sociedade.

Infelizmente, a deformação conceitual inserida na organização sócio-política brasileira distancia o cidadão de uma atitude de responsabilidade perante o processo de elaboração de políticas públicas e da legislação que as regulamentam (AGUIAR, 1994). Este fato faz com que aqueles setores, em geral, organizados segundo os fortes interesses políticos - econômicos tenham oportunidade de exporem e fazerem valer suas opiniões e ainda, formando opiniões nos demais setores, muitas vezes em detrimentos de outras visões, que realmente, os beneficiariam.

Contudo, à medida que os usuários têm a oportunidade de ampliar o nível de informação e a consciência do impacto das ações públicas em sua vida, aumenta a percepção do sentido de eficácia política e o reconhecimento de alternativas possíveis, além de ampliar a identificação de sujeitos semelhantes, promovendo a formação de grupos, nos quais aumenta a possibilidade de organização e fortalecimento sócio-político (LA PALOMBARA , 1982).

Segundo Borba \& MERCANTE (2001), a participação social é, ao mesmo tempo, meta e meio, pois, em acordo com os pressupostos adotados para as ações educativas, o processo é tão importante quanto o resultado. $\mathrm{Ou}$ seja, a aprendizagem da participação é um dos maiores incentivos à capacidade humana de gerar e viabilizar análises e soluções, contribuindo para, efetivamente, construir um espaço democrático, como se pretende que seja o Comitê de Bacias Hidrográficas. 


\section{Conclusões}

A restrição do conhecimento aos interiores dos muros acadêmicos, a manipulação da mídia (em sua maioria, principal divulgadora dos jargões políticos dos setores economicamente mais fortes), a cooptação do paradigma do "desenvolvimento sustentável" nos discursos e programas políticos, sem efetivá-los no projeto e planejamento de desenvolvimento do país, fazem com que as alternativas já existentes para a maioria dos problemas ambientais, fiquem esquecidos.

Portanto, é muito difícil para a nossa sociedade, assumir o valor econômico da degradação provocada pelas atividades antrópicas. No entanto, só através de ações de educação ambiental, que socialize as informações existentes, conduzindo a conscientização, possibilitará a intervenção efetiva da sociedade civil, quanto ao que realmente deseja para si e sua comunidade.

\section{Referências}

AGUIAR, R. Direito do meio ambiente e participação popular. Ministério do Meio Ambiente. Brasília-DF, 1994.

BANCO MUNDIAL. La ordenación de los recursos hídricos. 1994.

BORBA, S. \& MERCANTE, M. A Pressupostos teóricos para a promoção da participação social no processo de gestão de recursos hídricos em Mato Grosso do Sul. In: IV CONGRESSO NACIONAL DE RECURSOS HÍDRICOS. Anais... Foz do Iguaçu-PR, 2001.

BORSOL, Z.M.F \& TORRES, S.D.A. A política de recursos hídricos no Brasil. Revista BNDES, n. 8, 1997. Disponível em: <http://www.bndes.gov.br/conhecimento/ publicacoes/catalogo/rev_10a6.asp>. Acesso em: 05 nov. 2005.

BROCH, S. A. O. Desenvolvimento sustentável de Mato Grosso do Sul: O desafio da gestão integrada dos recursos hídricos. 151p. Tese de Mestrado Universidade de Brasília - Centro de Desenvolvimento Sustentável, Brasília-DF, 2001.

FREITAS, M.V. de; SANTOS, A H. M. Importância da água e da informação hidrológica. In: FREITAS, M.A.V. de (Org.). O estado das águas no Brasil. Brasília-DF: ANEEL, SIR,MMA,SRH, 1999.

LA PALOMBARA, J. A política no interior das nações. Ed. Universidade de Brasília-DF, 1982. (Coleção Pensamento Político, v.60).

LIMA, E. Recurso estratégico do século: água. Disponível em: <http://www. cnpma.embrapa.br/ novidades/ agua $>$.

MARTINS, C. R, VALENCIO, N.F.L.da S.; LEME, A. A valoração dos recursos hídricos e impasse sócioambiental na agricultura paulista: alguns desafios para a gestão de políticas públicas. In: IV CONGRESSO NACIONAL DE RECURSOS HÍDRICOS. Anais... Foz do Iguaçu-PR, 2001.

PAIVA, M.de F. A. A cobrança pelo uso da água como incentivo à redução dos níveis de poluição hídrica. In: IV CONGRESSO NACIONAL DE RECURSOS HÍDRICOS. Anais... Foz do Iguaçu-PR, 2001.

VETORATTO, G. A cobrança pelo uso dos recursos hídricos como instrumento estadual de política macroeconômica. In: $23^{a}$ Procuradoria de Justiça Criminal de Goiás. Caderno de Doutrina - Ambiental. 2004. 11 p. Disponível em: <http://www.serrano.neves.com.br>. Acesso em: 04 nov. 2005.

VIANNA, et al. Educação ambiental: uma abordagem pedagógica dos temas da atualidade. 2.ed. rev. e ampl. Rio de Janeiro: Centro de Documentação e Informação - CEDI, 1994 (WORLD BANK WATER DEMAND RESEARCH TEAM, The demand for water in rural areas : determinants and policy implications. Research Observer 8 (1), 1993). 